\title{
Evaluation of a psychoeducational intervention including emotional intelligence to increase treatment adherence in rheumatoid arthritis (A pilot study)
}

\author{
E. Cárdenas-Cloud ${ }^{1}$, A.J.L. Brambila-Tapia ${ }^{2}$, R.M. Meda-Lara ${ }^{2}$, \\ F.d.J. Pérez-Vázquez ${ }^{3,4}$, E. Chavarría-Ávila ${ }^{4}$, F.J. Romero Abundis ${ }^{4}$, \\ M. Vázquez-del-Mercado ${ }^{4,5}$ \\ ${ }^{1}$ Master's degree in Health Psychology, Department of Basic Psychology, Centro Universitario \\ de Ciencias de la Salud (CUCS), Universidad de Guadalajara, Guadalajara, Jalisco, Mexico; \\ ${ }^{2}$ Department of Basic Psychology, Centro Universitario de Ciencias de la Salud (CUCS), \\ University of Guadalajara, Guadalajara, Jalisco, Mexico; \\ ${ }^{3}$ University of Guadalajara, University Center of Health Sciences, Department of Philosophical, \\ Methodological and Instrumental Disciplines, Guadalajara, Jalisco, Mexico; \\ ${ }^{4}$ University of Guadalajara, University Center for Health Sciences, Institute for Research in Rheumatology and \\ the Musculoskeletal System, Department of Molecular Biology and Genomics Guadalajara, Jalisco, Mexico; \\ ${ }^{5}$ Rheumatology Service, Hospital Civil de Guadalajara Dr. Juan I. Menchaca, Guadalajara, Jalisco, Mexico
}

\section{SUMMARY}

Our objective was to perform two studies: a cross-sectional study in order to identify the main psychological variables associated to treatment adherence in rheumatoid arthritis and an intervention based on psychoeducation to assess its impact on the variables identified in the first study.

We measured treatment adherence, self-efficacy, beliefs about medication, emotional intelligence and disability along with personal and disease variables in the cross-sectional study and the same variables were measured in the intervention before and after the program and 3 months later in 2 groups (an experimental group and an active control group).

In the cross-sectional study $(\mathrm{N}=33)$ we found that the variables most associated with treatment adherence were emotional clarity $(r=0.352, p<0.05)$ and emotional repair $(r=0.363, p<0.05)$. In the intervention, we divided the patients into 2 groups: the control group $(\mathrm{N}=7)$ and the intervention group $(\mathrm{N}=10)$. At the end of the study and at follow-up, we found a significant increase in adherence and self-efficacy in the intervention group, when compared with the control group. Emotional clarity was increased only in the post-test, and at follow up a decrease in beliefs of concern about medication was found.

Psychoeducational programs based on information about the disease and its treatment together with emotional management are effective in increasing treatment adherence in the long term.

Key words: Rheumatoid arthritis, treatment adherence, disability, emotional intelligence, psychoeducation.

Reumatismo, 2021; 73 (3): 167-173

\section{INTRODUCTION}

A dherence is defined as the process by which patients take their medications as prescribed (1). Rheumatoid arthritis (RA) is a chronic inflammatory disease with variable adherence rates (30-80\%) depending on the population studied. Lack of adherence has been associated with disease flares and increased disability $(2,3)$. The variables associated with adherence in RA are thera- py-related factors (naive versus experienced users, steroid use, drug load and number of side effects), condition-related factors (disease activity, perceived health), patient-related factors (self-efficacy and beliefs about medications), socioeconomic factors (patient education and presence of children) and healthcare system factors (satisfaction with the consultation) (2).

On the other hand, different intervention programs have been evaluated to increase
Corresponding authors: Aniel Jessica Leticia Brambila-Tapia Department of Basic Psychology, Centro Universitario de Ciencias de la Salud (CUCS), University of Guadalajara, Sierra Mojada \#950, Colonia Independencia, Guadalajara, Jalisco, México

E-mail: aniel.brambila@academicos.udg.mx Dr. Mónica Vázquez-del-Mercado Instituto de Investigación en Reumatología y del Sistema Musculoesqueletico. Sierra Mojada \#950,

Colonia Independencia, Guadalajara, Jalisco, México

E-mail: dravme@hotmail.com 
adherence in these patients, where educational programs and customized cognitive behavioral therapy showed effectiveness to increase it in the long term (3). These programs have been focused on giving the patient information about RA, its symptoms and treatment as well as on psychological factors like improving mood and coping strategies $(4,5)$. One study showed effectiveness including the patient-doctor communication and concordance in treatment (6), while another study showed that text message reminders were effective in increasing treatment adherence (7).

However, besides self-efficacy and beliefs about medication, few psychological variables have been studied in relation to adherence in RA (optimism, social support, stress, coping and perceived barriers) (2). Therefore, in this study, we decided to investigate the relationship between emotional intelligence, defined as the individuals' beliefs about their own emotional abilities, including the ability to observe and think about their feelings, as well as to understand and regulate their emotional states (8); together with self-efficacy, defined as the ability to adequately manage a wide range of everyday life stressors (9), and beliefs about medication with treatment adherence in RA and to implement an intervention based on these variables in order to increase treatment adherence.

\section{PATIENTS AND METHODS}

\section{Study 1. Identifying the variables associated with adherence}

In the first study, a cross-sectional study was performed, in which we contacted RA patients from a list of 130 patients who attended the rheumatology service of a third level hospital, and fulfilled both the 1987 and 2010 classification criteria for the disease $(10,11)$. Those who accepted to participate answered a number of questions concerning a series of variables including socio-demographic data, disease variables and the following clinical and psychological variables:

1) physical functioning, measured with the health assessment questionnaire (HAQ), with a range of $0-3$, in which a higher score indicates a higher disability $(12,13)$;
2) emotional intelligence, measured with the Spanish validation of the Trait Meta Mood Scale (TMMS-24) (8), with a range of 8-40 for the three subscales (emotional attention, emotional clarity and emotional repair), in which a higher score indicates a higher emotional intelligence;

3) self-efficacy, measured on the basis of 6 out of the 10 items of the Spanish validation of the general self-efficacy scale (9), with a range of 6-24, in which a higher score indicates a higher self-efficacy;

4) beliefs about medication, measured with the Spanish validation of Beliefs Medication Questionnaire (BMQ) (14), with a range for overuse and harm of 4-20, and for necessity and concern of 5-25, in which a higher score indicates higher beliefs of each subscale;

5) treatment adherence, measured with the Spanish validation of the simplified medication adherence questionnaire (SMAQ), with a range of 0-9, in which a higher score indicates a higher adherence (15, 16). All scales and subscales had an adequate reported consistency, measured with Cronbach's alpha $(\geq 0.70)$.

\section{Study 2. Evaluation of an intervention to increase adherence}

Patients in study one were invited to participate in an intervention (clinical trial) with an active control group, conducted in parallel with a 1:1 allocation, in order to investigate how to increase treatment adherence. The patients that accepted to participate were then assigned into two study groups. Patient assignment was performed according to the order of inclusion in the study (not randomized). The intervention group received four 2-hour sessions a week, in which they were informed about the disease, its symptoms, the myths about the disease, the importance of exercise, the treatment and the most frequent mistakes in treatment intake, and the myths about medication. The last two sessions were devoted to the importance of emotion recognition, how to control emotions, the relationship between emotions and health and how to express the emotions assertively for the sake of effective communication. In all the ses- 
sions the patients performed a review of the previous session, performed exercises during the session and had homework, such as creating a weekly medication calendar, identifying their emotions, bringing the last medical prescription and doing physical activity. The active control group only received a manual with some information provided in the sessions about disease and treatment, emotional management, exercise and healthy nutrition. The same psychologist performed all the interventions and evaluations and also gave the manual to the control group. All interventions and data collection were performed at the University of Guadalajara facilities.

The following variables were measured one week before the first intervention and one week after the last intervention: treatment adherence, self-efficacy, beliefs about medication, emotional intelligence and disability with the previously mentioned instruments. In addition, the DAS-28 index was also used to measure disease activity (17). A followup was performed 3 months later in which all the variables, with the exception of DAS28 , were measured again.

\section{Statistical analysis}

Descriptive statistics consisted in means and standard deviations (SD) for quantitative variables and frequencies and percentages for qualitative ones. To analyze the relationship between the studied variables we used Pearson's and Spearman's correlation tests depending on whether the data distribution was parametric or non-parametric respectively. To compare quantitative variables between study groups at baseline we used Mann Whitney U test (considering the small sample size), and for qualitative variables we used the Chi squared test. In order to compare the difference in each variable after the intervention (post-intervention minus baseline) and in the follow up (followup minus baseline) we used Mann Whitney U test. All analyses were conducted with SPSS v.21.0.

\section{Ethics}

The protocol was performed according to the code of ethics of the World Medical As- sociation (Declaration of Helsinki) and was approved by the Ethics Committee of the Hospital. All patients signed an informed consent.

\section{RESULTS: STUDY 1}

A total of 33 patients with the following characteristics accepted to participate: 32 $(97.0 \%)$ were women with a mean age \pm SD of $48.4 \pm 11.4$ year; their mean time since diagnosis \pm SD was $9.2 \pm 7.7$ years; 19 $(57.6 \%)$ were married; most patients, i.e. 27 $(81.8 \%)$, had an education level of high school or lower and $20(60.6 \%)$ did not work. With respect to disability, in 18 $(54.5 \%)$ patients the disease did not affect mobility (HAQ $<0.5)$ and in terms of adherence $32(97.0 \%)$ where non-adherent, with at least some answers indicative of non-adherence.

When we performed the correlations of socio-demographic and psychological variables with adherence, we observed that the subscales of emotional intelligence showed that emotional clarity $(\mathrm{R}=0.352, \mathrm{p}=0.044)$ and emotional repair $(\mathrm{R}=0.360, \mathrm{p}=0.040)$ were the only psychological variables associ-

Table I - Correlations between socio-demographic, disease and psychological variables with adherence and disability.

\begin{tabular}{|l|c|c|}
\hline Variable & Adherence (N =33) & Disability (N=33) \\
\hline Age & 0.037 & 0.116 \\
\hline Time since diagnosis & 0.055 & -0.312 \\
\hline Number of children & -0.095 & -0.091 \\
\hline Education level & 0.247 & -0.191 \\
\hline Number of drugs & $-0.363^{*}$ & 0.109 \\
\hline Self-efficacy & -0.056 & -0.098 \\
\hline Emotional clarity & $0.352^{*}$ & -0.318 \\
\hline Emotional attention & -0.249 & 0.038 \\
\hline Emotional repair & $0.360^{*}$ & -0.338 \\
\hline BMQ necessity & 0.080 & -0.152 \\
\hline BMQ harms & -0.128 & -0.030 \\
\hline BMQ overuse & -0.151 & -0.060 \\
\hline BMQ concern & -0.281 & 0.163 \\
\hline Adherence & - & -0.243 \\
\hline
\end{tabular}

${ }^{*} p$ value $<0.05, p$ value obtained with Pearson and Spearman correlation tests, depending of the data distribution. 
ated (positively) with treatment adherence. We also observed a negative correlation between the number of drugs prescribed and adherence $(\mathrm{R}=-0.363, \mathrm{p}=0.038)$. In addition, emotional clarity $(\mathrm{R}=-0.318, \mathrm{p}=0.071)$ and emotional repair $(\mathrm{R}=-0.338, \mathrm{p}=0.055)(\mathrm{Ta}-$ ble I) presented a tendency to be associated (negatively) with disability (with an even higher R score than adherence).

\section{RESULTS: STUDY 2}

A total of 17 patients (all women) accepted to participate. They were assigned to the control group $(\mathrm{N}=7)$ or the intervention group $(\mathrm{N}=10)$. No significant differences were observed in the socio-demographic, disease or psychological variables studied at baseline (Table II). All patients were taking Disease Modifying Anti-Rheumatic Drugs (DMARDs), most methotrexate ( $\mathrm{N}=16$, $94.1 \%), 5$ of them in combination with sulfasalazine, one in combination with sulfasalazine and rituximab, and one was taking sulfasalazine alone (5.9\%).

At the end of the intervention, we observed a significant increase in treatment adher- ence (quantitatively measured), self-efficacy and emotional clarity, although no differences were observed in disability or disease activity (Table III). At follow-up, we still observed a significant increase in adherence and self-efficacy compared to baseline. Likewise, a significant decrease in the BMQ subscale of concern about the use of medication in the experimental group was observed as well as a borderline decrease in the BMQ subscale of overuse of medication (Table IV). No harms or unintended effects were observed.

\section{DISCUSSION AND CONCLUSIONS}

Treatment adherence is the result of different factors including personal psychological factors that can be modified in order to improve them. In the cross-sectional study, we corroborated the association between the number of drugs prescribed and a diminished adherence (18). However, unlike other studies, we did not find a correlation between beliefs about medication or self-efficacy and treatment adherence (18-20). This

Table II - Characteristics of intervention groups at baseline.

\begin{tabular}{|c|c|c|c|}
\hline & Experimental group $(\mathrm{N}=10)$ & Control group (N=7) & $p$ value \\
\hline Time since diagnosis, mean \pm SD & $8.29 \pm 4.38$ & $12.80 \pm 9.24$ & 0.519 \\
\hline Age, mean $\pm S D$ & $49.3 \pm 14.5$ & $49.3 \pm 12.2$ & 0.617 \\
\hline Number of drugs & $1.4 \pm 0.7$ & $1.7 \pm 0.5$ & 0.45 \\
\hline $\begin{array}{l}\text { Adherence (SMAQ), mean } \pm S D \\
\text { Adherent patients, } \mathrm{N}(\%)\end{array}$ & $\begin{array}{c}6.6 \pm 1.3 \\
1(10)\end{array}$ & $\begin{array}{c}6.9 \pm 1.1 \\
0(0)\end{array}$ & $\begin{array}{l}0.65 \\
1.00\end{array}$ \\
\hline $\begin{array}{l}\text { Beliefs about medication }(\mathrm{BMQ}) \text {, mean } \pm S D \\
\text { Overuse } \\
\text { Harm } \\
\text { Necessity } \\
\text { Concern }\end{array}$ & $\begin{array}{l}11.3 \pm 2.6 \\
11.0 \pm 3.7 \\
21.6 \pm 4.1 \\
12.4 \pm 4.4\end{array}$ & $\begin{array}{c}10.6 \pm 3.5 \\
8.2 \pm 3.3 \\
21.5 \pm 2.7 \\
13.2 \pm 7.7\end{array}$ & $\begin{array}{l}0.608 \\
0.091 \\
0.716 \\
0.979\end{array}$ \\
\hline Self-efficacy, mean $\pm S D$ & $19.0 \pm 3.7$ & $19.6 \pm 3.1$ & 0.687 \\
\hline Disability $(\mathrm{HAQ})$, mean $\pm \mathrm{SD}$ & $0.5 \pm 0.33$ & $0.22 \pm 0.33$ & 0.40 \\
\hline $\begin{array}{l}\text { Emotional intelligence (TMMS-24), mean } \pm \text { SD } \\
\text { Emotional attention } \\
\text { Emotional clarity } \\
\text { Emotional repair }\end{array}$ & $\begin{array}{l}24.6 \pm 8.3 \\
29.9 \pm 9.6 \\
36.3 \pm 4.8\end{array}$ & $\begin{array}{l}24.6 \pm 7.6 \\
29.7 \pm 9.1 \\
32.6 \pm 6.7\end{array}$ & $\begin{array}{l}1.00 \\
0.905 \\
0.369\end{array}$ \\
\hline Disease activity, (DAS-28), median (ranges) & $2.9(2.2-3.1)$ & $2.4(1.8-2.9)$ & 0.230 \\
\hline
\end{tabular}

SD: Standard deviation * $p$ value obtained with Mann Whitney $U$ test and Chi squared test. Ranges of the tests: Adherence (0-9), beliefs about medication: overuse (4-20), harm (4-20), necessity (5-25), concern (5-25); test of disability (0-3), emotional intelligence, for the three subscales (8-40); self-efficacy (0-24), and DAS-28-PCR (0-9). SMAQ: Simplified Medication Adherence Questionnaire, HAQ: Health Assessment Questionnaire, BMQ: Beliefs Medication Questionnaire, TMMS: Trait Meta Mood Scale, DAS: Disease Activity Score. 
Table III - Intergroup comparisons of the difference (post-intervention less baseline) of the variables at the end of the intervention.

\begin{tabular}{|l|c|c|c|}
\hline Variable & $\begin{array}{c}\text { Control group } \\
(\mathbf{N}=7)\end{array}$ & $\begin{array}{c}\text { Experimental Group } \\
(\mathbf{N}=10)\end{array}$ & $\begin{array}{c}\text { p value } \\
\text { (Post-intervention) }\end{array}$ \\
\hline Adherence (SMAQ), mean $\pm S D$ & $-0.7 \pm 1.7$ & $1.4 \pm 1.2$ & $0.016^{*}$ \\
Adherent patients, $\mathrm{N}(\%)^{\text {a }}$ & $1(14.3)$ & $4(40.0)$ & 0.33 \\
\hline Beliefs about medication, (BMQ) mean $\pm S D$ & & & \\
Overuse & $0.0 \pm 2.5$ & $-1.1 \pm 2.5$ & 0.100 \\
Harm & $-0.7 \pm 4.3$ & $-4.1 \pm 3.9$ & 0.313 \\
Necessity & $1.0 \pm 4.2$ & $-0.1 \pm 1.9$ & 0.513 \\
Concern & $-1.3 \pm 4.0$ & $-4.1 \pm 4.8$ & 0.161 \\
\hline Self-efficacy, mean $\pm S D$ & $-0.6 \pm 1.1$ & $3.1 \pm 3.6$ & $0.042^{*}$ \\
\hline Disability (HAQ), mean $\pm S D$ & $-0.2 \pm 0.2$ & $-0.1 \pm 0.3$ & 0.261 \\
\hline Emotional intelligence (TMMS-24), mean $\pm S D$ & & & \\
Emotional attention & $-1.0 \pm 8.3$ & $-4.6 \pm 6.6$ & 0.258 \\
Emotional clarity & $-2.0 \pm 6.3$ & $7.4 \pm 7.3$ & $0.019^{*}$ \\
Emotional repair & $0.9 \pm 4.5$ & $3.9 \pm 5.6$ & 0.201 \\
\hline Disease activity (DAS-28), median (ranges) & $-0.02(-0.3-1.0)$ & $0.21(-0.1-0.3)$ & 1.00 \\
\hline
\end{tabular}

SD: Standard deviation ${ }^{*} p$ value<0.05. P value obtained with Mann-Whitney U test and Chi squared. SMAQ: Simplified Medication Adherence Questionnaire, HAQ: Health Assessment Questionnaire, BMQ: Beliefs Medication Questionnaire, TMMS: Trait Meta Mood Scale, DAS: Disease Activity Index Score. ${ }^{a}$ Adherent patients correspond to the number of adherent patients in each group at the end of the intervention.

Table IV - Intergroup comparisons of the difference (follow-up less baseline) of the variables at follow-up.

\begin{tabular}{|l|c|c|c|}
\hline Variable & $\begin{array}{c}\text { Control group } \\
(\mathbf{N}=7)\end{array}$ & $\begin{array}{c}\text { Experimental Group } \\
(\mathbf{N}=10)\end{array}$ & p value \\
\hline Adherence (SMAQ), mean $\pm S D$ & $-1.1 \pm 1.8$ & $1.4 \pm 1.6$ & $0.012^{*}$ \\
Adherent patients, $\mathrm{N}(\%)^{\mathrm{a}}$ & $0(0)$ & $4(40)$ & 0.220 \\
\hline Beliefs about medication (BMQ), mean $\pm \mathrm{SD}$ & & & \\
Overuse & $0.4 \pm 3.3$ & $-1.6 \pm 2.6$ & 0.057 \\
Harm & $2.9 \pm 5.2$ & $-3.7 \pm 3.7$ & 0.111 \\
Necessity & $-0.6 \pm 4.7$ & $-1.1 \pm 4.1$ & 0.870 \\
Concern & $2.0 \pm 4.3$ & $-4.3 \pm 5.5$ & $0.013^{*}$ \\
\hline Self-efficacy, mean $\pm S D$ & $-0.4 \pm 1.8$ & $3.3 \pm 3.5$ & $0.043^{*}$ \\
\hline Disability (HAQ), mean $\pm S D$ & $0.1 \pm 0.2$ & $-0.01 \pm 0.1$ & 0.582 \\
\hline Emotional intelligence (TMMS-24), mean \pm SD & & & \\
Emotional attention & $-1.6 \pm 10.3$ & $-1.0 \pm 6.1$ & 0.981 \\
Emotional clarity & $-2.0 \pm 9.4$ & $7.7 \pm 8.8$ & 0.139 \\
Emotional repair & $0.9 \pm 6.6$ & $5.3 \pm 6.7$ & 0.151 \\
\hline
\end{tabular}

SD: Standard deviation * $p$ value< 0.05 . P value obtained with Mann-Whitney U test and chi squared test. SMAQ: Simplified Medication Adherence Questionnaire, HAQ: Health Assessment Questionnaire, BMQ: Beliefs Medication Questionnaire, TMMS: Trait Meta Mood Scale. ${ }^{\text {a }}$ Adherent patients correspond to the number of adherent patients in each group at the follow-up.

may be due to the small sample size. However, considering the $\mathrm{R}$ values, it is possible that with a bigger sample size, only a low negative correlation between concern about medication and adherence would have been found. Nevertheless, the highest association found (although low) was between two subscales of emotional intelligence (clarity and repair) and adherence, which also presented a tendency to be associated (negatively) with disability. These associations may be explained by the relationship that exists between emotional regulation and better accomplishment of objectives and better use of time, probably improving memory and diminishing the concern about medication. This is supported by the negative correlation between emotional clarity and beliefs of concern about medication $(r=-0.375$, $\mathrm{p}=0.031$ ). A borderline negative correlation 
between emotional clarity and beliefs of harm due to medication was also found ( $\mathrm{r}=-$ $0.313, \mathrm{p}=0.076$ ), suggesting that, when emotional clarity is high, the irrational beliefs of harm due to medication declines. Likewise, the borderline negative association between emotional intelligence and disability may be explained by psychoneuroimmunology, which investigates psychological wellbeing, a variable associated with emotional regulation, as a cause of a diminished inflammation (21-23).

Considering the results of the cross-sectional study, we performed an intervention based on psychoeducation in the disease, its treatment and emotional intelligence. We observed a significant increase in adherence at the end of the intervention and 3 months later. It is important to consider that the differences were observed with the quantitative measure, while no significance was observed when the patients were classified as adherent or non-adherent. This is explained by the small sample size and the strictness of the test (a single question indicative of non-adherence classifies the patient as nonadherent). In addition, significant improvements in self-efficacy, emotional clarity and beliefs about medication were also observed. These results corroborate the associations observed in the cross-sectional study and suggest that psychoeducation in emotional intelligence together with education in the disease and its treatment can increase treatment adherence in the long term. The main limitation of the study is the small sample size, mainly in the intervention experiment, and the lack of randomization and blindness. However, its main strength is the inclusion of variables that are mainly associated with adherence, as well as emotional intelligence, a new psychological variable which was not previously investigated.

In conclusion, to the best of our knowledge, this is the first study that evaluates emotional intelligence in relation with treatment adherence in RA. In this respect, we found that emotional clarity and emotional repair were significantly associated with treatment adherence so much so that an intervention that incorporated these variables, together with disease and treatment information, achieved a significant increase in treatment adherence, emotional intelligence, self-efficacy and useful beliefs about medication. These results suggest that, in addition to information about the disease and its treatment, psychoeducation about emotion management in educational programs is important in order to improve treatment adherence in the longterm, as well as beliefs about medication, and self-efficacy, and could also improve disability in these patients. However, more studies with larger sample sizes are needed.

\section{Conflict of interests}

The authors have no conflict of interests to declare.

\section{Funding}

No funding resources were required.

\section{REFERENCES}

1. Wabe N, Lee A, Wechalekar M, et al. Factors associated with medication adherence in a longitudinal study of rheumatoid arthritis patients. Int J Clin Pract. 2019; 73: e13375.

2. van den Bemt BJ, Zwikker HE, van den Ende $\mathrm{CH}$. Medication adherence in patients with rheumatoid arthritis: a critical appraisal of the existing literature. Exp Rev Clin Immunol. 2012; 8: 337-351.

3. Lavielle M, Puyraimond-Zemmour D, Romand $\mathrm{X}$, et al. Methods to improve medication adherence in patients with chronic inflammatory rheumatic diseases: a systematic literature review. RMD Open. 2018; 4: e000684.

4. Evers A WM, Kraaimaat FW, van Riel PLCM, de Jong AJL. Tailored cognitive-behavioral therapy in early rheumatoid arthritis for patients at risk: a randomized controlled trial. Pain. 2002; 100: 141-153.

5. Hill J, Bird H, Johnson S. Effect of patient education on adherence to drug treatment for rheumatoid arthritis: a randomised controlled trial. Ann Rheum Dis. 2001; 60: 869-875.

6. Ravindran V, Jadhav R. The effect of rheumatoid arthritis disease education on adherence to medications and followup in Kerala, India. J Rheumatol. 2013; 40: 1460-1461.

7. Mary A, Boursier A, Desailly Henry I, et al. Mobile phone text messages improve treatment adherence in patients taking methotrexate for rheumatoid arthritis: a randomized pilot study. Arthrit Care Res. 2019; 71: 1344-1352.

8. Fernandez-Berrocal P, Extremera N, Ramos N. Validity and reliability of the Spanish modified version of the trait meta-mood scale. Psychol. Rep. 2004; 94: 751-755. 
9. Sanjuán-Suárez P, Pérez-García AM, Bermúdez-Moreno J. Escala de autoeficacia general: datos psicométricos de la adaptación para población española. Psicothema. 2000; 12: 509513.

10. Arnett FC, Edworthy SM, Bloch DA, et al. The American Rheumatism Association 1987 revised criteria for the classification of rheumatoid arthritis. Arthrit Rheum. 1988; 31: 315-324.

11. Aletaha D, Neogi T, Silman AJ, et al. Rheumatoid arthritis classification criteria: An American College of Rheumatology/European League Against Rheumatism collaborative initiative. Arthrit Rheum. 2010; 62: 2569-2581.

12. Bruce B, Fries JF. The Health Assessment Questionnaire (HAQ). Clin Exp Rheumatol. 2005; 23: S14-18.

13. Durán J, Domínguez A, Espinoza M. Evaluation of the Health Assessment Questionnaire Disability Index in Chilean patients with rheumatoid arthritis. Rev Med Chil. 2019; 147: 612617.

14. Beléndez-Vázquez M, Herández-Mijárez A, Horne R, Weinman J. Evaluación de las creencias sobre el tratamiento: validez y fiabilidad de la version española del Beliefs about Medicines questionnaire. Int J Clin Health Psychol. 2007; 7: 767-779.

15. Ortega Suárez FJ, Sánchez Plumed J, Pérez Valentín MA, et al. Grupo de Estudio Vatren. Validation on the simplified medication adherence questionnaire (SMAQ) in renal transplant patients on tacrolimus. Nefrologia. 2011; 31: 690-696.

16. Knobel H, Alonso J, Casado JL, et al. GEEMA Study Group. Validation of a simplified medi- cation adherence questionnaire in a large cohort of HIV-infected patients: the GEEMA Study 2002. AIDS. 2003; 16: 605-613.

17. Prevoo MLL, Van'T Hof MA, Kuper, HH, et al. Modified disease activity scores that include twenty-eight-joint counts development and validation in a prospective longitudinal study of patients with rheumatoid arthritis. Arthrit Rheum. 1995; 38: 44-48.

18. Treharne G, Lyons A, Kitas G. Medication adherence in rheumatoid arthritis: effects of psychosocial factors. Psychol Health Med. 2004; 9: 337-343.

19. De Klerk E. Measurement of patient compliance on drug therapy an overview. In Vingerhoets A (Ed.), Advances in behavioral medicine assessment. London: Harwood academic publishers; 2001.

20. Brus H, van de Laar M, Taal E, et al. Determinants of compliance with medication in patients with rheumatoid arthritis: the importance of self-efficacy expectations. Patient Educ Couns. 1999; 36: 57-64.

21. McEwen BS, Gray JD, Nasca C. 60 Years of Neuroendocrinology: Redefining neuroendocrinology: stress, sex and cognitive and emotional regulation. J Endocrinol. 2015; 226: T67-T83.

22. Irwin MR, Cole SW. Reciprocal regulation of the neural and innate immune systems. Nature Rev Immunol. 2011; 11: 625-632.

23. Pariante CM. Why are depressed patients inflamed? A reflection on 20 years of research on depression, glucocorticoid resistance and inflammation. Eur Neuropsychopharmacol. 2017; 27: 554-559. 